\title{
Home dampness, current allergic diseases, and respiratory infections among young adults
}

\author{
M Kilpeläinen, E O Terho, H Helenius, M Koskenvuo
}

\begin{abstract}
Background-The relation between home dampness and respiratory symptoms among adults is well confirmed, but data on specific allergic diseases and respiratory infections is more limited. Individual factors that may enhance susceptibility to the effects of home dampness are mainly unknown.

Methods-The association between home dampness and current physician diagnosed asthma, allergic rhinitis, allergic conjunctivitis, atopic dermatitis, common colds, and bacterial respiratory infections was studied in a questionnaire survey of 10667 Finnish first year university students aged 18-25 years. The dampness categories analysed were visible mould and visible mould or damp stains or water damage during the last year. In multivariate analyses adjustment was made for parental education, active and passive smoking, type and place of residence, pets, and wall to wall carpets. The interaction effect of atopic heredity and dampness was investigated.
\end{abstract}

Results-Visible mould or damp stains or water damage was reported by $15.0 \%$ of the respondents. In multivariate models there was a positive association between home dampness and current asthma, allergic rhinitis, and atopic dermatitis, as well as common colds $\geqslant 4$ times per year and other respiratory infections, but not between home dampness and allergic conjunctivitis. The strongest association was found between exposure to visible mould and asthma (OR 2.21, 95\% CI 1.48 to 3.28 ) and common colds (OR $1.49,95 \%$ CI 1.18 to 1.87$)$. The risk of current asthma in damp homes was highest among subjects with atopic heredity.

Conclusions-The risk of current asthma, allergic rhinitis, and atopic dermatitis was higher in damp homes. Of the respiratory infections, the risk of common colds was most clearly increased.

(Thorax 2001;56:462-467)

Keywords: asthma; allergic rhinitis; atopic dermatitis; dampness

Even in the cold dry climate of northern Europe, people are frequently exposed to damp living $^{1}$ and direct or indirect effects of home dampness may lead to respiratory or allergic disease or persistence of symptoms. In population studies among adults, after adjusting for social status, possible over-reporting of symptoms, and effects of active and passive smoking, a positive association has been established between home dampness and respiratory symptoms..$^{2-5}$ In addition, some studies have related home dampness to a greater risk of respiratory infections. ${ }^{5}$ There are few data on the association between dampness and specific atopic disease in adults, ${ }^{5}$ and these report an association with asthma ${ }^{37}$ and with selfreported atopic eczema and allergic rhinitis. ${ }^{5}$

The mechanisms by which home dampness is associated with respiratory symptoms and disease are apparently numerous. Sensitisation to house dust mite ${ }^{8}$ and moulds, ${ }^{9}$ the growth of which is favoured by home dampness, nonspecific inflammatory mechanisms promoted by exposure to bacterial and mould cell wall products, ${ }^{10}$ and irritant effects of volatile substances ${ }^{11}$ emitted by moulds have been suggested. The different health outcomes such as asthma and respiratory infections promoted by dampness can mainly be defined by individual factors. There is evidence for a greater risk of respiratory symptoms in atopic children exposed to moulds, ${ }^{8}{ }^{12}$ but the individual characteristics which predispose to the effects of home dampness are mainly unknown.

Using a validated questionnaire, we studied the association between reported home dampness and current asthma, allergic rhinitis and conjunctivitis, atopic dermatitis, common colds, and other respiratory infections in 10667 Finnish first year university students aged 18-25 years. The influence of the interaction between atopic heredity and dampness on the diseases was investigated.

\section{Methods}

STUDY SUBJECTS

A postal questionnaire was sent to all 14212 first year university students in 1995-1996 in Finland, and data were obtained from 10667 (response rate $75.0 \%)$. Of these, $4164(39.0 \%)$ were men and $6503(61.0 \%)$ were women. The mean (SD) age of the respondents was 20.9 (1.6) years (range 18-25).

QUESTIONS ON HOME DAMPNESS AND OTHER

EXPLANATORY VARIABLES

Questions on possible explanatory variables of asthma and allergic disease, including questions on home dampness, were assessed. The questions on dampness were as follows: (1) "Have you had mould growth on the surfaces of any of your dwellings during the last year?" (2) "Have you had damp stains, for example, on the walls or on the ceilings of any of your dwellings during the last year?" (3) "Has there 
Table 1 Characteristics of subjects with reported exposure to home dampness * and those without home dampness

\begin{tabular}{|c|c|c|c|}
\hline & $\begin{array}{l}\text { Reported home } \\
\text { dampness* }(\%)\end{array}$ & $\begin{array}{l}\text { No home } \\
\text { dampness (\%) }\end{array}$ & $\begin{array}{l}p \text { value } \\
\left(\chi^{2} \text { test }\right)\end{array}$ \\
\hline \multicolumn{4}{|l|}{ Parental education } \\
\hline Low & 29.0 & 29.3 & \\
\hline Middle & 38.1 & 36.6 & \\
\hline High & 32.9 & 34.2 & 0.478 \\
\hline \multicolumn{4}{|l|}{ Smoking } \\
\hline Non-smoker & 81.3 & 81.3 & \\
\hline Ex-smoker & 3.6 & 3.5 & \\
\hline Current smoker & 15.1 & 15.2 & 0.969 \\
\hline Passive smoking & 9.6 & 8.3 & 0.092 \\
\hline Pets & 40.0 & 37.0 & 0.022 \\
\hline Wall to wall carpets & 12.3 & 9.2 & 0.001 \\
\hline \multicolumn{4}{|l|}{ Heating system } \\
\hline Central heating & 72.6 & 74.3 & 0.142 \\
\hline Electrical heating & 21.7 & 18.0 & 0.001 \\
\hline Wood stove heating & 8.6 & 7.4 & 0.107 \\
\hline \multicolumn{4}{|l|}{ Household members } \\
\hline Living alone & 5.7 & 6.8 & \\
\hline 1-4 persons & 66.4 & 67.8 & \\
\hline 5 or more persons & 27.9 & 25.4 & 0.048 \\
\hline \multicolumn{4}{|l|}{ Place of residence } \\
\hline Urban & 83.1 & 85.5 & \\
\hline Farm & 7.0 & 6.5 & \\
\hline Rural non-farm & 9.9 & 8.0 & 0.034 \\
\hline \multicolumn{4}{|l|}{ Type of residence } \\
\hline One family or terraced house & 53.9 & 49.8 & \\
\hline Block of flats & 45.5 & 50.1 & 0.001 \\
\hline
\end{tabular}

^Reported visible mould or damp stains or water damage in the home within last year.

been a leak or water damage in any of your dwellings during the last year?" Two definitions of home dampness were then formed: visible mould (a positive response to question 1), and visible mould or damp stains or water damage (questions 1,2, or 3 ) in the home within the last year.

Confounding factors were selected by preliminary analysis (table 1 ). Parental education as a measure of the socioeconomic status of the family was defined on three levels: the low level of parental education included unskilled, semiskilled or skilled workers, and the high level consisted of university graduates. Current smokers were analysed against ex-smokers (gave up smoking at least 6 months ago) and lifetime non-smokers. Passive smoking included subjects with daily exposure to other person's smoking at home. Ownership of furry pets or birds, wall to wall carpets, and living with $0-4$ persons compared with $\geqslant 5$ persons during the previous year were analysed. Place of residence was regarded on three levels: farm, rural non-farm, and urban residence during the previous year. Living in a block of flats was compared with a one family and terraced house, wooden houses were compared with houses made of concrete or brick, houses built before 1970 were compared with newer ones, and electrical heating was compared with other forms of heating such as wood stove or central heating.

QUESTIONS ON ASTHMA, ATOPIC DISEASES, AND RESPIRATORY INFECTIONS

Current diseases were assessed by positive answers to the following questions ${ }^{13}$ :

Current asthma

- "Have you ever had asthma?"

- "If so, has a doctor diagnosed the disease?"

- "Have you had symptoms of asthma or wheezing during the last year?"
Current allergic rhinitis

- "Have you ever had "hay fever" or other allergic nasal symptoms (sneezing, itchy, runny nose) from pollen or animals?"

Current allergic conjunctivitis

- "Have you ever had allergic eye symptoms (watering, itching, redness, swelling of the eyelids) from pollen or animals?”

\section{Current atopic dermatitis}

- "Have you ever had an itchy rash called atopic eczema or eczema in the folds of the elbows or behind the knees?"

In addition, reports of a doctor's diagnosis and symptoms during the last year for each atopic disease were requested.

The occurrence of common colds and other respiratory infections was assessed by asking the question: "During the past year did you have flu without fever or flu with fever 0 times, 1-3 times, 4 times, or more often?" The frequency of infections suspected to be of bacterial origin was determined from the question: "During the past year did you have an infection in the lungs (pneumonia), in the bronchi (bronchitis), in the sinuses (sinusitis), in the middle ear (otitis media), or in the adenoids (tonsillitis) 0 times, 1-3 times, 4 times, or more often?" Days on antibiotic treatment were graded as follows: none, $<10$ days, $10-59$ days, $\geqslant 60$ days per year.

VALIDATION OF QUESTIONS ON CURRENT ASTHMA AND ATOPIC DISEASES

Questions on current asthma and atopic diseases were validated in a clinical subsample of 290 subjects with asthmatic symptoms during their lifetime. The validity measures were calculated after weighting the clinical subsample by the proportion of subjects with asthmatic symptoms in the original questionnaire study. ${ }^{14}$ Criteria for current asthma included asthmatic symptoms during the last year at chest physician's interview and obstructive spirometry or positive methacholine challenge. The specificity of current asthma was 0.99 and the sensitivity was 0.18 . Criteria for current allergic rhinitis and conjunctivitis included symptoms during the last year at interview and at least one positive skin prick test result $(\geqslant 3 \mathrm{~mm}$ ) or specific IgE (RAST class $\geqslant 1$ ) in Phadiatop Combi (Pharmacia Upjohn, Sweden). The specificity of current allergic rhinitis was 0.96 and the sensitivity 0.40 . For allergic conjunctivitis the specificity and sensitivity were 0.98 and 0.25 , respectively. When analysed against current atopic dermatitis at dermatologist's examination, the specificity of current atopic dermatitis was 0.95 and the sensitivity 0.23 .

ANALYSIS OF DATA

Subjects with current physician diagnosed asthma, allergic rhinitis, allergic conjunctivitis, or atopic dermatitis were compared with the others in each disease category. Subjects who had a common cold $\geqslant 4$ times per year were 
Table 2 Association of current asthma, allergic diseases, and respiratory infections with home dampness during last year in two dampness categories (crude and adjusted odds ratios (OR) with $95 \%$ confidence intervals)

\begin{tabular}{|c|c|c|c|c|}
\hline \multirow[b]{2}{*}{ Disorder } & \multicolumn{2}{|l|}{ Visible mould } & \multicolumn{2}{|c|}{ Visible mould/damp stains/water damage } \\
\hline & Crude OR $(95 \% \mathrm{CI})$ & Adjusted OR† $(95 \% \mathrm{CI})$ & Crude OR $(95 \% \mathrm{CI})$ & Adjusted OR† (95\% CI) \\
\hline Asthma & $2.15^{\star \star \star}(1.48$ to 3.12$)$ & $2.21^{\star \star \star}(1.48$ to 3.28$)$ & $1.54^{\star \star}(1.17$ to 2.01$)$ & $1.66^{\star \star \star}(1.25$ to 2.19$)$ \\
\hline Allergic rhinitis & $1.29^{\star}(1.01$ to 1.63$)$ & $1.29^{\star}(1.01$ to 1.66$)$ & $1.25^{\star \star}(1.08$ to 1.45$)$ & $1.30^{\star \star \star}(1.12$ to 1.51$)$ \\
\hline Allergic conjunctivitis & $1.00(0.72$ to 1.38$)$ & $0.95(0.68$ to 1.34$)$ & $1.11(0.92$ to 1.34$)$ & $1.12(0.92$ to 1.36$)$ \\
\hline Atopic dermatitis & $1.27(0.94$ to 1.72$)$ & $1.31(0.96$ to 1.79$)$ & $1.28^{\star \star}(1.07$ to 1.54$)$ & $1.29^{\star \star}(1.06$ to 1.56$)$ \\
\hline Common cold $\geqslant 4$ times within last year & $1.49^{\star \star \star}(1.18$ to 1.87$)$ & $1.48^{\star \star}(1.17$ to 1.88$)$ & $1.29^{\star \star \star}(1.11$ to 1.50$)$ & $1.28^{\star \star \star}(1.09$ to 1.47$)$ \\
\hline Other respiratory infections $\ddagger$ & $1.15(0.95$ to 1.40$)$ & $1.12(0.91$ to 0.36$)$ & $1.15^{\star}(1.03$ to 1.29$)$ & $1.16^{\star}(1.03$ to 1.31$)$ \\
\hline
\end{tabular}

${ }^{\star} \mathrm{p}<0.05 ;{ }^{\star \star} \mathrm{p}<0.01 ;{ }^{\star \star \star} \mathrm{p}<0.001$

†Adjusted for parental education, active and passive smoking, pets, wall to to to wall carpets, place of residence (farm, rural non-farm, urban), and type of residence (block of flats $v$ other).

$\ddagger$ Tonsillitis, otitis media, sinusitis, bronchitis or pneumonia at least once within last year.

compared with those with less frequent common colds, subjects who had at least one respiratory infection suspected to be of bacterial origin (pneumonia, bronchitis, sinusitis, otitis media, and tonsillitis) were compared with those without any of these infections, and subjects receiving antibiotic treatment on $<10$ days during the previous year were compared with those treated with antibiotics for at least 10 days.

Explanatory variables that were significantly related to home dampness in any of the two dampness categories were added to the multiple logistic regression analyses by stepwise method. Parental education and active smoking were also included. Variables that were significantly associated with at least one disease in the multivariate analyses were then tested, and thus parental education, active and passive smoking, pets, wall to wall carpets, place of residence (farm, rural non-farm, urban), and type of residence (block of flats versus the others) were included. The interaction effect of home dampness and atopic heredity was also tested. The independent associations between the diseases and the two home dampness categories and the other explanatory variables were expressed as odds ratios (OR) with $95 \%$ confidence intervals (CI). p values of $<0.05$ or CIs not including 1.0 were regarded as significant. The analysis was performed by SAS System for Windows, release 6.12/1996 (SAS Institute Inc, 1996). ${ }^{15}$

\section{Results}

Of the subjects who responded, 4.9\% (517/ 10640 ) reported visible mould in the home within the last year, $12.2 \% \quad(1301 / 10648)$ reported visible mould or damp stains, and $15.0 \%$ (1602/10 649) reported visible mould or damp stains or water damage. When subjects in the highest category of home dampness were compared with those in homes without dampness, the occurrence of current asthma was $4.3 \%$ v $2.8 \%(\mathrm{p}=0.002)$, current allergic rhinitis $16.2 \%$ v $13.4 \% \quad(\mathrm{p}=0.003)$, current allergic conjunctivitis $8.8 \%$ v $8.0 \%$ $(\mathrm{p}=0.278)$, and current atopic dermatitis $9.4 \%$ v 7.5\% $(\mathrm{p}=0.008) ; 15.7 \%$ v $12.6 \%(\mathrm{p}=0.001)$ reported four or more common colds during the last year and $37.2 \% v 34.0 \% \quad(p=0.015)$ reported having at least one of pneumonia, bronchitis, sinusitis, otitis media, or tonsillitis.

The possible confounding variables associated with home dampness (visible mould or damp stains or water damage) are shown in table 1. Pets, wall to wall carpets, and electrical heating were more common in homes with dampness. Subjects with home dampness lived more often in a one family or terraced house, in a rural area, and in large households.

Data on the association between the diseases and exposure to visible mould and to visible mould or damp stains or water damage are shown in table 2 . In both categories of home dampness there was a positive association between damp living and current asthma and allergic diseases. In the multivariate analyses adjustment was made for parental education, current active and passive smoking, pets, wall to wall carpets, place of residence (farm, rural non-farm, urban), and type of residence (block of flats $v$ one family and terraced houses). The significant positive association between the two categories of home dampness and current asthma, allergic rhinitis, but not that of allergic conjunctivitis (table 2) was confirmed in the multivariate analysis. Current atopic dermatitis was independently associated with home dampness in the analysis, including the wider definition of home dampness (table 2).

Current asthma, allergic rhinitis, allergic conjunctivitis, and atopic dermatitis were significantly negatively associated with the presence of pets (adjusted OR from 0.33 to 0.68 ) and wall to wall carpets (adjusted odds ratios from 0.40 to 0.69 ). Among those who lived on a farm, the risk of current allergic rhinitis (OR $0.74,95 \%$ CI 0.56 to 0.99 ) and conjunctivitis (OR $0.53,95 \%$ CI 0.35 to 0.82 ) was lower. A high level of parental education increased the risk of allergic rhinitis (OR 1.17, 95\% CI 1.01 to 1.35 ) and conjunctivitis (OR $1.28,95 \%$ CI 1.07 to 1.54 ). Current active and passive smoking were not related to asthma and allergic rhinitis. Allergic conjunctivitis was negatively associated with active smoking (OR $0.85,95 \%$ CI 0.77 to 0.95 ) and atopic dermatitis was negatively associated with passive smoking (OR 0.62, 95\% CI 0.45 to 0.86 ).

The impact of atopic heredity on the association between home dampness and the diseases is shown in table 3. Exposure to home dampness was related to current asthma among subjects with parental asthma or atopic disease, but not among those without atopic heredity. The interacting effect of parental atopic disease and home dampness on current asthma was statistically significant $(\mathrm{p}=0.033)$. 
Table 3 Prevalence (\%) of physician diagnosed asthma, allergic diseases, respiratory infections, and antibiotic treatment during previous year in homes with and without dampness according to atopic heredity

\begin{tabular}{|c|c|c|c|c|c|}
\hline & $\begin{array}{l}\text { Parental asthma or } \\
\text { atopic disease }\end{array}$ & $\begin{array}{l}\text { Visible mould or damp } \\
\text { stains or water damage }\end{array}$ & No dampness & $\begin{array}{l}p \text { value } \\
\left(\chi^{2} \text { test }\right)\end{array}$ & $\begin{array}{l}\text { p value for } \\
\text { interaction }\end{array}$ \\
\hline Asthma & $\begin{array}{l}\text { Yes } \\
\text { No }\end{array}$ & $\begin{array}{l}7.4(53 / 718) \\
1.7(15 / 863)\end{array}$ & $\begin{array}{l}4.2(149 / 3570) \\
1.9(102 / 5378)\end{array}$ & $\begin{array}{l}0.001 \\
0.750\end{array}$ & 0.033 \\
\hline Allergic rhinitis & $\begin{array}{l}\text { Yes } \\
\text { No }\end{array}$ & $\begin{array}{l}22.9(164 / 717) \\
10.8(93 / 860)\end{array}$ & $\begin{array}{l}19.7(701 / 3561) \\
9.2(494 / 5363)\end{array}$ & $\begin{array}{l}0.053 \\
0.135\end{array}$ & 0.942 \\
\hline Allergic conjunctivitis & $\begin{array}{l}\text { Yes } \\
\text { No }\end{array}$ & $\begin{array}{l}12.1(87 / 718) \\
6.3(54 / 864)\end{array}$ & $\begin{array}{l}11.5(410 / 3571) \\
5.8(311 / 5379)\end{array}$ & $\begin{array}{l}0.627 \\
0.586\end{array}$ & 0.899 \\
\hline Atopic dermatitis & $\begin{array}{l}\text { Yes } \\
\text { No }\end{array}$ & $\begin{array}{l}12.7(91 / 717) \\
6.7(58 / 860)\end{array}$ & $\begin{array}{l}10.9(388 / 3560) \\
5.2(281 / 5355)\end{array}$ & $\begin{array}{l}0.165 \\
0.073\end{array}$ & 0.596 \\
\hline Common cold $\geqslant 4$ per year & $\begin{array}{l}\text { Yes } \\
\text { No }\end{array}$ & $\begin{array}{l}16.6(119 / 717) \\
14.9(128 / 860)\end{array}$ & $\begin{array}{l}14.1(502 / 3562) \\
11.6(623 / 5365)\end{array}$ & $\begin{array}{l}0.082 \\
0.006\end{array}$ & 0.547 \\
\hline $\begin{array}{l}\text { Other respiratory infection } \\
\geqslant 1 \text { per yeart }\end{array}$ & $\begin{array}{l}\text { Yes } \\
\text { No }\end{array}$ & $\begin{array}{l}39.8(266 / 669) \\
35.0(273 / 781)\end{array}$ & $\begin{array}{l}37.5(1247 / 3325) \\
31.5(1573 / 4990)\end{array}$ & $\begin{array}{l}0.272 \\
0.056\end{array}$ & 0.633 \\
\hline
\end{tabular}

$\star$ Interaction of atopic heredity and dampness.

†Tonsillitis, otitis media, bronchitis, sinusitis, or pneumonia.

There was a fairly strong positive association between the number of common colds ( $\geqslant 4$ during last year) and home dampness (excess of $29-48 \%$, table 2) and a weak negative association between dampness and residence in a block of flats (OR $0.83,95 \%$ CI 0.74 to 0.95). The association between home dampness and common colds was strongest among subjects without atopic heredity (table 3 ). The interacting effect of non-atopic heredity and home dampness on common colds did not, however, reach statistical significance (table 3).

The association between reported respiratory infections such as pneumonia, bronchitis, sinusitis, otitis media, and tonsillitis and home dampness was shown only in the home dampness category with visible mould or damp stains or water damage (table 2). Current smoking was a stronger predictor of these respiratory infections than home dampness (OR $1.19,95 \%$ CI 1.12 to 1.26 ), but it was not a predictor of common colds (OR 1.05, 95\% CI 0.97 to 1.14 ). There was a positive correlation between visible mould or damp stains or water damage and at least 10 days on antibiotic treatment $(p=0.001)$. Of subjects with atopic heredity $32.6 \% v 28.5 \%(\mathrm{p}=0.030)$ had taken antibiotics for at least 10 days during the previous year, compared with $26.1 \%$ v $22.7 \%$ $(p=0.028)$ of those without atopic heredity. Subjects with atopic heredity were treated significantly more often with antibiotics $(\mathrm{p}<0.001)$ but no interaction between atopic heredity and home dampness on antibiotic use could be shown $(\mathrm{p}=0.799)$.

\section{Discussion}

HOME DAMPNESS AND ALLERGIC DISEASES

In this study of young Finnish adults the risk of current asthma was about twice as high when exposed to home dampness. The positive association between home dampness and current allergic rhinitis and atopic dermatitis was weaker, and no such relation was found with current allergic conjunctivitis. Neither the definition of dampness nor factors related to housing and environment made major changes to the results. There was a significantly greater risk of current asthma in subjects with both a genetic predisposition to asthma or atopy and exposure to dampness.

The length of exposure, prevalence of dampness, and definitions of diseases have varied in different studies, and all these factors influence the reported risk. We considered the reporting of visible mould, damp stains and water damage to be reliable only for the previous year and analysed subjects with currently symptomatic diseases confirmed by a physician. The presence of mould or dampness in the home was lower than in many other European reports, but comparable to another Finnish questionnaire survey among adults. ${ }^{5}$ The low prevalence of mould problems $(15.0 \%$ reported mould or damp stains or water damage) and current diseases evidently led to weaker associations than in studies with more frequent mould problems ${ }^{3}$ or those using lifetime selfreported diseases. ${ }^{5}$ The study by Pirhonen $e t a l^{5}$ was designed to investigate only symptoms and reported a somewhat larger risk of allergic rhinitis and eczema, but the risk of asthma was not influenced by home dampness. The twofold risk of asthma reported in this study was comparable to that found in three other studies. $^{3416}$

Reporting bias may be introduced and would mainly concern exposure to home dampness. We included several housing characteristics, some of which have earlier been related to measures of mould levels in the indoor air. In a Swedish study indoor Aspergillus levels correlated with wall to wall carpets, ${ }^{12}$ and in an Australian study high amounts of fungal propagules in indoor air were related to the presence of pets and wall to wall carpets. ${ }^{17}$ In the present study there were more pets and wall to wall carpets in households with home dampness, thus indirectly suggesting reliability of self-reporting of damp problems. On the other hand, the association between reported visible mould and high levels of specific fungal spores $^{9}$ and ergosterol ${ }^{17}$ as a marker of cumulative fungal exposure is well established.

The habit of ill people and physicians to seek an explanation for symptoms might lead to overestimation of the association between home dampness and disease. In England both 
asthmatic and non-asthmatic subjects tended to underestimate the mould problem when compared with professional assessors, ${ }^{7}$ but overestimation of symptoms occurred in subjects investigated for a damp problem. ${ }^{28}$ In adults the main associations between damp housing and symptoms seem to remain after adjusting for the possible "complainer" effect (exclusion of subjects with chronic complaints $^{3-5}$ or subjects with depression and stress $^{5}$ from the analyses). To control for reporting bias we used questions on currently symptomatic physician diagnosed diseases found to be specific and thus excluding false positive responses. On the other hand, the sensitivity of these questions was quite low and therefore it is possible that subjects with more severe disease were included. Subjects with current diseases may also be more aware of home dampness and more likely to remove the suspected harmful factor. In a cross sectional study this might result in a weaker association-or even a negative one-between exposure and the disease. Such a strong negative association was shown between pets, wall to wall carpets and current asthma and atopic diseases, apparently reflecting allergen avoidance undertaken by symptomatic subjects.

The inclusion of several confounding variables in the analyses did not change the main results. The independent negative relation between living on a farm and allergic rhinitis and conjunctivitis is in agreement with recent studies ${ }^{18-21}$ and could be explained by microbial exposure of farmer's children in early childhood and adolescence favouring a non-atopic phenotype. ${ }^{22}$ Urban and rural non-farming environments were not related to the risk of disease, supporting the finding that outdoor pollution is not a significant risk factor for atopic disease. ${ }^{23}$

Epidemiological studies in adults have shown comparable associations between home dampness and the occurrence of respiratory symptoms among allergic and non-allergic subjects, ${ }^{3-5}$ suggesting that damp related symptoms in adults are not promoted by atopy. In the present study subjects with atopic heredity were at a greater risk of developing asthma when exposed to damp living. Sensitisation to pets in Scandinavia, ${ }^{24}$ to house dust mites in a warm humid climate, ${ }^{25}$ and to Aspergillus in the inland climate of Australia ${ }^{26}$ have been reported for allergen related risk factors of asthma. In a study in young asthmatic children the combination of exposure to cats and home dampness multiplied the risk of sensitisation to cats. ${ }^{27}$ In a recent Swedish case-control study in 25-44 year old subjects, sensitisation to Cladosporium and Aspergillus was more prevalent in damp dwellings and the sensitisation was related to current asthma. ${ }^{28}$ These studies suggest that some factor directly or indirectly related to home dampness could enhance sensitisation and partly explain the subsequent asthma. The present finding of the interacting effect of heredity and exposure to home dampness on the risk of asthma also suggests that the factor linking dampness and asthma might be sensitisation to pets, and even to house dust mite, in Finnish homes with dampness.

HOME DAMPNESS AND RESPIRATORY INFECTIONS The independent positive association between home dampness and occurrence of common colds at least four times within the last year was established, even after adjusting for active and passive smoking. Visible mould, damp stains, and water damage were also a weak independent risk factor for respiratory infections of suspected bacterial origin such as pneumonia and otitis media, even though the impact of active smoking was stronger. Such an association was not established, however, when only more severe exposure to visible mould was considered. Although the risk of common colds related to home dampness was highest in subjects without atopic heredity, no significant interaction was found between common colds or other respiratory infections, home dampness, and atopic inheritance.

In earlier studies sore throat, ${ }^{2}$ bronchitis, and common colds ${ }^{5}$ have been associated with home dampness. These symptoms may represent chronic irritation, and reliability of the questions regarding the actual respiratory infections can be disputed. In this study we found that the number of days with antibiotic treatment during the last year correlated significantly with both categories of home dampness. In Finland antibiotics are not available without a doctor's prescription which, in turn, means that the doctor considered the infection to be of bacterial origin. The number of subjects with at least one respiratory infection and antibiotic treatment for at least 10 days was quite high which suggests that doctors easily diagnose prolonged respiratory infections to be of bacterial origin and that they prescribe antibiotics more than is necessary.

Non-specific inflammatory mechanisms promoted by cell wall components of moulds ${ }^{10}{ }^{12}$ and volatile organic compounds ${ }^{11}$ excreted by moulds could explain the susceptibility to infection in homes with dampness. On the other hand, in the present study the greater risk of current asthma was not explained by the number of respiratory infections among asthmatic subjects (data not shown). In atopic and asthmatic subjects the pre-existing inflammation may be enhanced by non-specific inflammatory ${ }^{12}$ and irritating ${ }^{28}$ mechanisms induced by moulds. This could also explain the interaction between atopic heredity and home dampness on current asthma in the present study.

In conclusion, the results of this study suggest that home dampness at least maintains currently symptomatic asthma, ${ }^{29}$ allergic rhinitis, and atopic dermatitis and increases the susceptibility to common colds and possibly to other respiratory infections. The interaction of factors such as atopy and atopic heredity with dampness deserves further investigation. Moreover, research on housing characteristics which determine the growth of moulds is needed to prevent indoor exposure to dampness. 
The authors thank Mrs Anne Kaljonen for the data processing. The work was supported by grants from the Finnish Studen Health Service, the Social Insuran

Conflict of interest: none

1 Nevalainen A, Partanen P, Hyvärinen A, et al. Building moisture investigation: back to basics in identifying microbial problems. In: Morawska eds. Indoor air: an integrated approach. 1st ed. Exeter: BPC Wheatons Ltd, 1995: 485-8.

2 Platt SD, Martin CJ, Hunt SM, et al. Damp housing, mould growth and symptomatic health state. BMF 1989; 298 1673-8.

3 Dales RE, Burnett R, Zwanenburg H. Adverse health effects among adults exposed to dampness and molds. Am Rev Respir Dis 1991;143:505-9.

4 Brunekreef B. Damp housing and adult respiratory symptoms. Allergy 1992;47:498-502.

5 Pirhonen I, Nevalainen A, Husman T, et al. Home dampness, moulds and their influence on respiratory infections and symptoms in adults in Finland. Eur Respir $\mathcal{f}$ 1996;9:2618-22.

6 Martin CJ, Platt SD, Hunt SM. Housing conditions and ill health. BMF 1987;294:1125-7.

7 Williamson IJ, Martin CJ, McGill G, et al. Damp housing and asthma: a case control study. Thorax 1997; 52:229-34.

8 Verhoeff AP, van Strien RT, van Wijnen JH, et al. Damp housing and childhood respiratory symptoms: the role of sensitization to dust mites and molds. Am f Epidemiol 1995;141:103-10.

9 Garrett MH, Rayment PR, Hooper MA, et al. Indoor airborne fungal spores, house dampness and associations with environmental factors and respiratory health in children. Clin Exp Allergy 1998;28:459-67.

10 Thorn J, Rylander R. Airways inflammation and glucan in a rowhouse area. Am f Respir Crit Care Med 1998;157:1798803.

11 Becher R, Hongslo JK, Jantunen MJ, et al. Environmental chemicals relevant for respiratory hypersensitivity. Toxicol Lett 1996;86:155-62.

12 Wickman M, Gravesen S, Nordvall SL, et al. Indoor viable dust-bound microfungi in relation to residential characteristics, living habits, and symptoms in atopic and control istics, living habits, and symptoms in atopic and
children. 7 Allergy Clin Immunol 1992;89:752-9.

13 Susitaival P, Husman T, eds. The Tuohilampi questionnaire for population studies of hypersensitivity diseases of respiratory syspopulation studies of hypersensitivity disease of respiratory

14 Kilpeläinen M, Terho EO, Helenius $\mathrm{H}$, et al. Validation of a new questionnaire on asthma, allergic rhinitis and conjunctivitis among young adults. Allergy 2001 (in press).
15 SAS Institute. SAS/STAT software: changes and enhancements through release 6.11. Cary, NC: SAS Institute Inc, 1996.

16 Norbäck D, Björnsson E, Janson C, et al.Current asthma and biochemical signs of inflammation in relation to buildng dampness in dwellings. Int $f$ Tuberc Lung Dis 1999;3:368-76.

17 Dharmage S, Bailey M, Raven J, et al. Prevalence and residential determinants of fungi within homes in Melbourne, Australia. Clin Exp Allergy 1999;29:1481-9.

18 Braun-Fahrländer C, Gassner M, Grize L, et al. Prevalence of hay fever and allergic sensitisation in farmer's children and their peers living in the same rural community. Clin Exp Allergy 1999;29:28-34.

19 Von Ehrenstein OS, von Mutius E, Illi S, et al. Reduced risk of hay fever and asthma among children of farmers. Clin Exp Allergy 2000;30:187-93.

20 Riedler J, Eder W, Oberfeld G, et al. Austrian children living on a farm have less hay fever, asthma and allergic sensitization. Clin Exp Allergy 2000;30:194-200.

21 Kilpeläinen $\mathrm{M}$, Terho EO, Helenius $\mathrm{H}$, et al. Farm environment in childhood prevents the development of allergies. Clin Exp Allergy 2000;30:201-8.

22 Rook GAW, Stanford J. Give us this day our daily germs. Immunol Today 1998;3:113-16.

23 Charpin D, Pascal L, Birnbaum J, et al. Gaseous air pollution and atopy. Clin Exp Allergy 1999;29:1474-80.

24 Plaschke P, Janson C, Norrman E, et al. Association between atopic sensitization and asthma and bronchial hyperresponsiveness in Swedish adults: pets, and not mites, are the most important allergens. F Allergy Clin Immunol 1999;104: 58-65.

25 Sporik R, Holgate ST, Platts-Mills TAE, et al. Exposure to house dust mite allergen $(\operatorname{Der} p \mathrm{I})$ and the development of asthma in childhood: a prospective study. $N$ Engl $\mathcal{F} \mathrm{Med}$ 1990;323:502-7.

26 Peat JK, Tovey E, Mellis CM, et al. Importance of house dust mite and Alternaria allergens in childhood asthma: an epidemiological study in two climatic regions of Australia. Clin Exp Allergy 1993;23:812-20

27 Lindfors A, van Hage-Hamsten M, Rietz H, et al. Influence of interaction of environmental factors and sensitization in young asthmatic children. F Allergy Clin Immunol 1999;104: 755-62.

28 Pappas GP, Herbert RJ, Henderson W, et al. The respiratory effects of volatile organic conpounds. Int 7 Occup Environ Health 2000;6:1-8.

29 Nicolai T, Illi S, von Mutius E. Effect of dampness at home in childhood on bronchial hyperreactivity in adolescence. Thorax 1998;53:1035-40. 